DOI: 10.17707/AgricultForest.62.1.42

\author{
Milena MOTEVA, Velibor SPALEVIC, \\ Antoaneta GIGOVA, Vjekoslav TANASKOVIK ${ }^{1}$
}

\title{
WATER USE EFFICIENCY AND YIELD-DEPENDENCES FOR CANOLA (Brassica napus, L.) UNDER IRRIGATION
}

\begin{abstract}
SUMMARY
Worsened water availability conditions caused by the recent processes of climate warming evoke the attention of the scientists to the efficiency of the water use by crops. A useful tool for successful yield and water management is the yieldwater relationship. The goal of the paper is to study the interrelations between water, water use efficiency and yield of canola and to calibrate some yield-water dependencies which can be recommended for prediction of the irrigation water amounts and the yield. A moderately early canola hybrid (Brassica napus, L.) was studied for its sensitivity and response to water. A field experiment in Sofia region, Bulgaria, was conducted. Three levels of soil moisture conditions in a chromic luvisols were tested: rain-fed; deficit moisture, managed by $50 \%$ deficit irrigation; and normal moisture conditions, managed by full irrigation at a refill point $80 \%$ of field capacity. The data from the experiment was processed by analysis of variance and regression analysis. The results show that soil moisture level has statistically significant impact on the yield accumulation. It contributed to increasing the seed yield from a minimum $1.319 \mathrm{Mg} / \mathrm{ha}$ at $E T=189.0 \mathrm{~mm}$ under rain-fed conditions to a maximum of $4.889 \mathrm{Mg} / \mathrm{ha}$ at $E T=310.0 \mathrm{~mm}$ under normal moisture conditions. The maximum irrigation water use efficiency in the experiment was $1.78 \mathrm{~kg} / \mathrm{m}^{3}$ at an irrigation depth of $94 \mathrm{~mm}, E T=268.5 \mathrm{~mm}$ and seed yield $-4.189 \mathrm{Mg} / \mathrm{ha}$. The maximum water use efficiency occurs earlier than the maximum yield. By managing $12 \%$ less (than needed) seasonal evapotranspiration, the yield losses were only $6 \%$. Elasticity (sensitivity of the crop to water) can be used as an indicator for the critical range of the seasonal evapotranspiration, in which the water use efficiency and the yield are maximal $(0 \leq E W P \leq 1)$. The yield response factor $K_{\mathrm{y}}$ of FAO linear function was established as 1.52. The parameters of the local Davidov equations were calibrated as $a=3.53$ and $k=1.58$ for the single-power equation and $q=2.39$ and $r=13.63$ for the two-power equation. Davidov equations
\end{abstract}

\footnotetext{
${ }^{1}$ Milena Moteva, University of Architecture, Civil Engineering and Geodesy, Faculty of Geodesy, Department of Land Management and Agrarian Development, $1 \mathrm{Hr}$ Smirnenski, Blvd., 1046, BULGARIA; (corresponding author: milena_moteva@yahoo.com). Velibor Spalevic, University of Montenegro, Faculty of Philosophy Niksic, Department of Geography, MONTENEGRO; Antoaneta Gigova, Institute of Soil Science, Agro-Technology and Plant Protection, Department of Mechanization and Hydromelioration, Section Hydromelioration and Irrigation Scheduling of the Agricultural Crops, 3 Shose Bankya Str., 1331 Sofia, BULGARIA; Vjekoslav Tanaskovik, University St. Cyril and Methodius, Faculty of Agricultural Sciences and Food, 9 Gotse Delchev, Blvd., 1000 Skopje, MACEDONIA.

Notes: The authors declare that they have no conflicts of interest. Authorship Form signed online.
} 
are recommended with priority for forecasting of canola yields on the base of the seasonal crop evapotranspiration.

Keywords: canola, irrigation, water use efficiency, elasticity, FAO yield response factor, Davidov's equations, Bulgaria

\section{INTRODUCTION}

Worsened water availability conditions caused by the recent processes of climate warming evoke the attention of the scientists to the efficiency of the water use by crops. In the countries, where the water resources are insufficient and unevenly distributed over the territory, yield is predicted by means of models that guarantee high water use efficiency, for the purpose of obtaining economically acceptable production results. A useful tool for successful yield and water management in these models is the yield-water relationship, written down in different analytical forms with calibrated coefficients for particular crops and environments. The yield-water dependences describe the impact of water on the yield accumulation at different water supply levels. Some authors have the opinion that when crop suffers of an evenly distributed throughout the growing season water deficit, the yield is a linear function of the evapotranspiration (Jensen, 1968; Stewart et al., 1973; Doorenbos, Kassam, 1979; Tzakiris, 1981; Varlev, Popova., 1999, Varlev, 2004). Downey, 1972 notices that the plants grown in an open field are not exposed to constant water deficit because the evapotranspiration after rain or an irrigation application is the maximum. The water stress starts when the soil starts to dry. The dynamics of the soil water regime is a good reason to think that the yield losses are not a simple function of the evapotranspiration. The results from testing the impact of a proviso regular throughout the growing season water deficit have revealed so far that the yield losses are dependent on the weather conditions. There are many authors who think that the yield-water dependence is a power function, which can be represented by a series of two-incurvation curves with an inflection point. These authors are convinced that except the meteorological peculiarities of the individual years, the yield-water dependence reflects the biological characteristics of the crops (Pare, Olivier, 1969; Davidov, 1982, 2004; Mate, 2001; Zhukov, Davidov, 2003). Stewart et al. (1973) have established that the reduction of the yield is not proportionate to the reduction of the water given by irrigation. Consistent with that, Zhivkov, $(1994,1995)$ has obtained $4-10 \%$; 9-15\%, 14-25 and 51\% reduction of corn yield by 20, 40, 60, and $75 \%$ reduction of the irrigation depth. By applying 50\% irrigation water deficit the yield reduction of corn on haplic chernozems is around 5-6\% (Rafailov et al., 1998).

The goal of the paper is to study the interrelations between water, water use efficiency and yield of canola and to calibrate some yield-water dependencies which can be recommended for prediction of the irrigation water amounts and the yield in the temperate continental climate conditions of Bulgaria. 


\section{MATERIAL AND METHODS}

A field experiment with irrigation of winter canola was carried out in Sofia region, Bulgaria $\left(42.6^{\circ} \mathrm{N}, 550 \mathrm{~m}\right.$ a.s.l.) during three growing seasons 2010-2011, 2011-2012 and 2012-2013. The climate of the region is temperate-continental. The average annual temperature of the site is $10.3^{\circ} \mathrm{C}$. The place is one of the most humid in the country. The average annual precipitation is $610 \mathrm{~mm}$ (Geography of Bulgaria, 2002). The rainfall totals of the period March-July in 2011, 2012 and 2013 were $132.8,174.6$ and $187.6 \mathrm{~mm}$ respectively.

Table 1. Probability of exceedance

\begin{tabular}{|c|c|c|c|c|}
\hline Year & $\begin{array}{c}\text { March- } \\
\text { July }\end{array}$ & $\begin{array}{c}\text { Aarch- } \\
\text { April }\end{array}$ & $\begin{array}{c}\text { April- } \\
\text { June }\end{array}$ & $\begin{array}{c}\text { June- } \\
\text { July }\end{array}$ \\
\hline \multicolumn{5}{|c|}{ Rainfalls } \\
\hline 2011 & 85.0 & 100.0 & 100.0 & 20.0 \\
\hline 2012 & 92.5 & 97.5 & 80.0 & 95.0 \\
\hline 2013 & 60.0 & 80.0 & 35.0 & 30.0 \\
\hline \multicolumn{5}{|c|}{ Air Temperature } \\
\hline 2011 & 75.0 & 72.5 & 85.0 & 50.0 \\
\hline 2012 & 10.0 & 50.0 & 12.5 & 2.5 \\
\hline 2013 & 30.0 & 50.0 & 17.5 & 45.0 \\
\hline \multicolumn{5}{|c|}{ Vapour pressure deficit } \\
\hline 2011 & 35.0 & 60.0 & 55.0 & 25.0 \\
\hline 2012 & 5.0 & 12.5 & 5.0 & 5.0 \\
\hline 2013 & 52.5 & 65.0 & 22.5 & 65.0 \\
\hline
\end{tabular}

As to the 50-year (1974-2013)rainfall probability of exceedance, the period March-July in 2011 and 2012 was dry and average in 2013. Analogously, this period is featured cool in 2011 and warm in 2012 and 2013. As to vapour pressure deficit, it was dry in 2011 and 2012 and average in 2013 (Table 1).

The experiment was put in a randomized complete block design in three replications. Irrigation was in three levels: rain-fed, $50 \%$ deficit irrigation, and full irrigation at a refill point $80 \%$ of field capacity $\left(R P_{80}\right)$. The canola variety Triangle, which is popular on Bulgarian market, has been tested. The soil was chromic luvisols with total water content $T W C=327 \mathrm{~mm}$, available water content $A W C=165 \mathrm{~mm}$, and bulk density $\alpha=1.5 \mathrm{~g} / \mathrm{cm}^{3}$. Land preparation, fertilizers and weed control were applied according to the standard agricultural practices in the region. Sowing was done each year in the period $25-30^{\text {th }}$ September.

The irrigation application depth at $R P_{80}$ was $m=60 \mathrm{~mm}$ and was calculated as:

$$
m=10 H \alpha\left(\beta_{F C}-\beta_{R P_{s 0}}\right)
$$

where $\beta$ is the moisture percentage by weight (Kostyakov, 1951). The depth of root expansion was adopted as $H=1.0 \mathrm{~m}$. The soil water content in the root zone was estimated in each 10 days by the soil sampling method.

The 10-day crop evapotranspiration was calculated by the water balance equation:

$$
E T_{c}=W_{i-1}-W_{i}+m+R
$$

where $E T_{\mathrm{c}}-10$-day actual crop evapotranspiration, $\mathrm{mm} ; W_{\mathrm{i}-1}-$ soil water content in the $1-\mathrm{m}$ soil layer on the first day of the 10-day period, $\mathrm{mm} ; W_{\mathrm{i}}-$ soil water content in the $1-\mathrm{m}$ soil layer on the tenth day of the 10-day period, mm; $R$ - the 10-day effective rainfall total, $\mathrm{mm}$. The spring-summer evapotranspiration totals were calculated through summarizing the 10-day values. 
Variance analysis was applied to the yield results. Regression analysis was applied to establish the impact of the irrigation depth on the irrigation water use efficiency (Irr.WUE).

FAO yield-evapotranspiration dependence

$$
Y_{d e f}^{i} / Y_{\max }=1-K_{y}\left(1-E T_{d e f}^{i} / E T_{\max }\right) \text { (Doorenbos, Kassam, 1979) and }
$$

Davidov power equations

$$
\begin{aligned}
& Y_{d e f}^{i} / Y_{\max }=1-a\left(1-E T_{d e f}^{i} / E T_{\max }\right)^{k} \text { and } \\
& Y_{d e f}^{i} / Y_{\max }=\left(1-\left(1-E T_{\text {def }}^{i} / E T_{\max }\right)^{q}\right)^{r} \text { (Davidov, 1982, 2004) were calibrated, }
\end{aligned}
$$

where: $Y_{d e f}^{i}$ - yield under irrigation deficit in plot $i, \mathrm{Mg} / \mathrm{ha} ; Y_{\max }$ - yield under full irrigation, $\mathrm{Mg} / \mathrm{ha} ; E T_{\text {def }}^{i}$ - actual crop evapotranspiration at $Y_{d e f}^{i}, \mathrm{~mm} ; E T_{\max }-$ maximum evapotranspiration in the experiment $\mathrm{mm} ; a$ - parameter; $q$ - power index that reflects the impact of the water supply on the yield $(q<1), r$ - power index that reflects the sensibility of the crop to the water deficit; $k$ - power index; $K_{y}-$ yield factor (=const. for a certain crop).

Interrelations of yield, evapotranspiration, and water use efficiency were established from a marginal analysis of the water production functions (Liu et al., 2002).

\section{RESULTS AND DISCUSSION}

Following the dynamics of the meteorological conditions, in 2011 was given one irrigation application and in 2012 and 2013 - two irrigation applications.

Table 2. Results from the field experiment

\begin{tabular}{|c|l|c|c|c|}
\hline Year & \multicolumn{1}{|c|}{ Variants } & Irrigation depth, $\mathrm{mm}$ & ET, $\mathrm{mm}$ & Seed yield, $\mathrm{Mg} / \mathrm{ha}$ \\
\hline 2011 & Raifed & - & 189.8 & 1.319 \\
\hline & 50\% irrigation deficit & 30 & 228.2 & $3.894+++$ \\
\hline & Full irrigation & 60 & 260.0 & $4.889+++$ \\
\hline 2012 & Raifed & - & 220.6 & 2.833 \\
\hline & 50\% irrigation deficit & 60 & 255.3 & $3.838+$ \\
\hline & Full irrigation & 120 & 272.5 & $4.797+++$ \\
\hline 2013 & Raifed & - & 260.0 & 2.517 \\
\hline & 50\% irrigation deficit & 60 & 296.0 & $4.123+++$ \\
\hline & Full irrigation & 120 & 310.0 & $4.737+++$ \\
\hline
\end{tabular}

+significant at $\mathrm{P}=5 \%$; ++significant at $\mathrm{P}=1 \%$; +++significant at $\mathrm{P}=0.1 \%$

The results in Table 2 show significant impact of irrigation on the yield. The seed yield under rain-fed conditions varies from 1.319 to $2.833 \mathrm{Mg} / \mathrm{ha}$. The yield under $50 \%$ deficit irrigation varies from 3.838 to $4.123 \mathrm{Mg} / \mathrm{ha}$ and the yield increase insignificant at probability $\mathrm{P}=5 \%$ and $\mathrm{P}=0.1 \%$. The yield under full irrigation is considerably higher - from 4.737 to $4.889 \mathrm{Mg} / \mathrm{ha}$ and is significant at $\mathrm{P}=0.1 \%$. These results confirm the results, obtained in different parts of the world. As to Istanbulluoglu et al. (2010) and their review, the seed yield of canola, obtained in rain-fed and irrigation conditions, varies from 1.0 to $5.3 \mathrm{Mg} / \mathrm{ha}$. Alberta 
Agriculture (1980) reported for 1.0-2.6 Mg/ha seed yields without irrigation, which were considered good, and 3.2-4.0 Mg/ha under full irrigation. As to North (2010), the yield in rain-fed conditions in Australia also tended to be $1.7-1.8 \mathrm{Mg} / \mathrm{ha}$, while the best on-farm yields were 1.8-3.6 Mg/ha. The yields from the experimental fields were as high as 3.8-5.2 $\mathrm{Mg} / \mathrm{ha}$. The yield of irrigated winter canola in Nebraska, USA was reported to be $\approx 3.0 \mathrm{Mg} /$ ha (Aiken, Lamm, 2006).

Crop sensibility to water was evident from the relation ET increase - yieldincrease. It is seen in Table 2 that the actual evapotranspiration under rain-fed conditions is in the range of $189.8-260.0 \mathrm{~mm}$, in conditions of $50 \%$ irrigation deficit - 228.2-296.0 mm, and under full irrigation - 260.0-310.0 mm. By giving $50 \%$ of the necessary irrigational water in 2012-2013, ET increased with $14-16 \%$ while yield increased with 35-64\%. By giving the whole needed amount of irrigational water, ET increased with $19-24 \%$ and the yield - with $69-88 \%$. In 2011 , depending on the meteorological conditions, an increase of $20 \%$ and $37 \%$ of ET caused unproportioned double and triple yield increase respectively. These results are evidence for different efficiency of the irrigational water in the range of the irrigation depth (Fig. 1). It is seen that the irrigation water use efficiency (Irr.WUE), as dependent on the irrigation depth, increases in a polynomial law, and the approximation of the data has high coefficient of determination $R^{2}=0.67$.

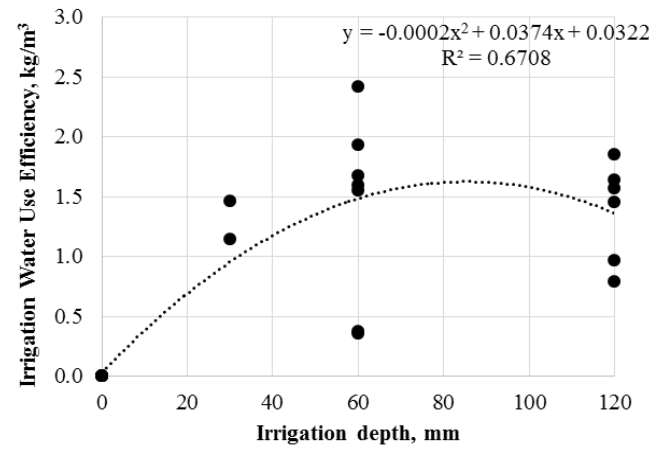

Figure 1. Impact of the irrigation depth on the irrigation water use efficiency

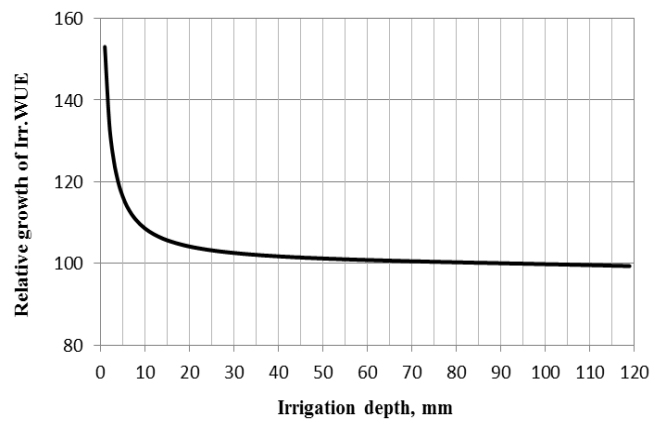

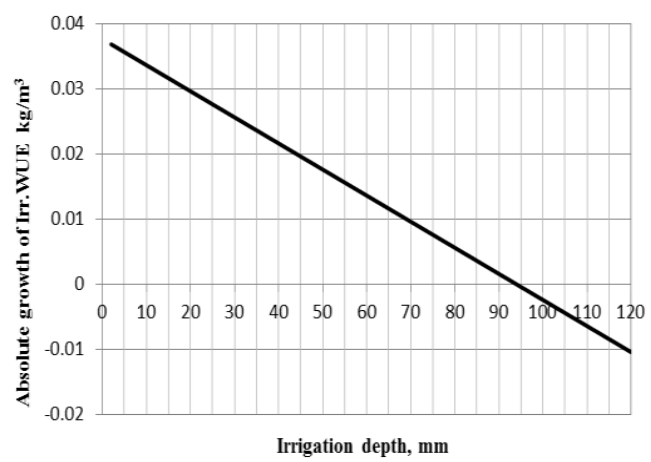

Figure 2. Rate of change of the Irrigation WUE

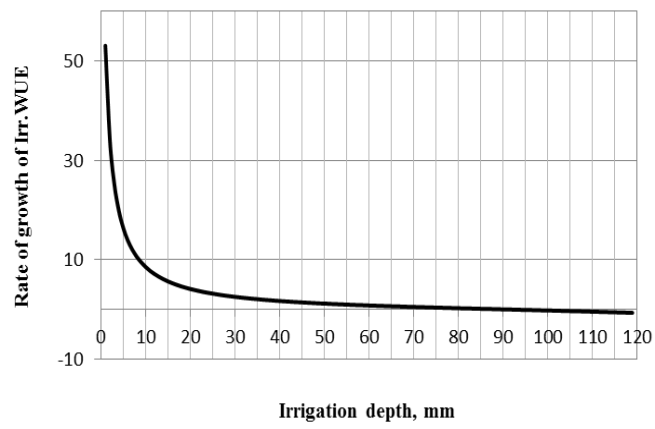

Figure 3. Relative growth (a) and rate of growth (b) of IrrWUE 
The absolute growth on a chain basis is const. $=-0.0004$, the average is $0.0186 \mathrm{~kg} / \mathrm{m}^{3}$ (Fig. 2). The line of the absolute growth crosses the $\mathrm{x}$-axis at the point when the relative growth is $100 \%$ (Fig 3a) and the rate of growth is zero (Fig. $3 \mathrm{~b}$ ). This point is the point of Irr.WUE $=1.78 \mathrm{~kg} / \mathrm{m}^{3}$. It is seen that Irr.WUE is maximum at irrigation depth $M=94 \mathrm{~mm}$. According to the quadric approximation, the relative growth and the rate of growth are greatest in the range approximately 0-30 $\mathrm{mm}$ of the irrigation depth, after which they sharply drop.

The results of the yield losses caused by the deficit of irrigation water make it possible to assess the nature of the "yield - irrigation depth" relationship in terms of its proportionality and to provide practical advice for the farmers for managing of the irrigation scheduling. The dependence of the yield losses on the irrigation depth in the experiment is linear and inversely proportional. The coefficient of proportionality is $a=-0.4943$ (Fig. 4). The relative yield losses when maintaining $50 \%$ deficit irrigation are $15-30 \%$ and when without irrigation are $30-50 \%$. Our results correspond to those reported by Fanaei et al. (2009) for 54-82\% relative yield losses in different drought conditions in comparison with optimum moisture conditions. As to them, drought is one of the strongest abiotic stress factors for the development and productivity of canola.

The issued up to here yield response to the irrigation water has only local meaning and is useful for local water management, confirmed by Hexem and Heady (1978). This relationship is influenced by the geographical location, especially by the weather. It is hardly applied for irrigation system management outside of the soil and climatic conditions for which this relationship is established. One of the more relevant and widely used relationships is that of the yield to evapotranspiration. It is universal and is bound mostly to the crop biology, to its sensitivity to water and ability to use water efficiently. After a thorough review of the research work in this field Vaux and Pruitt (1983) have concluded that crop yield is a linear function of the evapotranspiration. Their follower in Bulgaria is Varlev (2004). Dooreboos \& Kassam (1979) have introduced the crop factor $K_{\mathrm{y}}$ to describe the relationship between the yield loss and the deficit of evapotranspiration. On Fig. 4 is shown the yield-evapotranspiration relationship for canola, which is based on the data of the experiment. As a result of a regression analysis, the value of the crop factor was established as $K_{\mathrm{y}}=1.52$, with a high coefficient of determination $R^{2}=0.73$. The value of the crop factor, i.e. the slope of the straight line to $\mathrm{x}$-axis shows great sensitivity of canola to water. It reveals that a small deficit of evapotranspiration can cause high reduction of the yield:

$$
Y_{d e f}^{i} / Y_{\max }=1-1.52\left(1-E T_{d e f}^{i} / E T_{\max }\right) \text {. }
$$

The marginal approach to calculation of $K_{\mathrm{y}}$ (Liu et al., 2002) is based on the calculation of the marginal (maximum) water use efficiency (MWUE). The interrelations between the yield $(Y)$, the seasonal evapotranspiration $(E T)$ and $W U E$ based on the elasticity $(E W P)$ were studied. Elasticity is treated as the sensitivity of the crop to water in yield accumulation. Elasticity is limited by the maximum water 
use efficiency $(M W U E)$, which is the first derivative of the yieldevapotranspiration function, and can be expressed as:

$$
E W P=M W U E / W U E=(d Y / Y) /(d E T / E T) .
$$

It is evident that elasticity is different in different parts of the yieldevapotranspiration function.

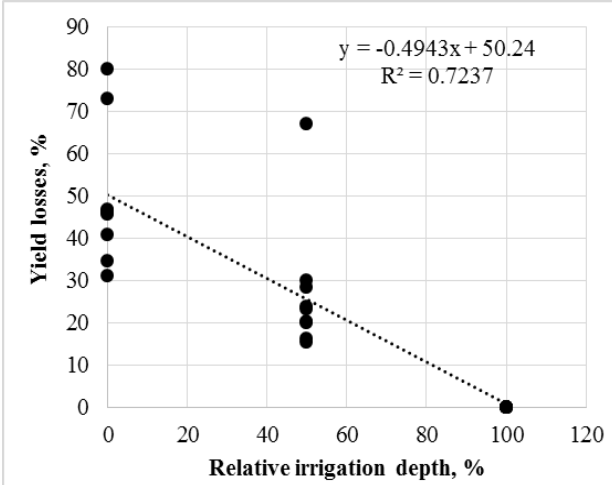

Figure 4. Relative yield losses, $\%$

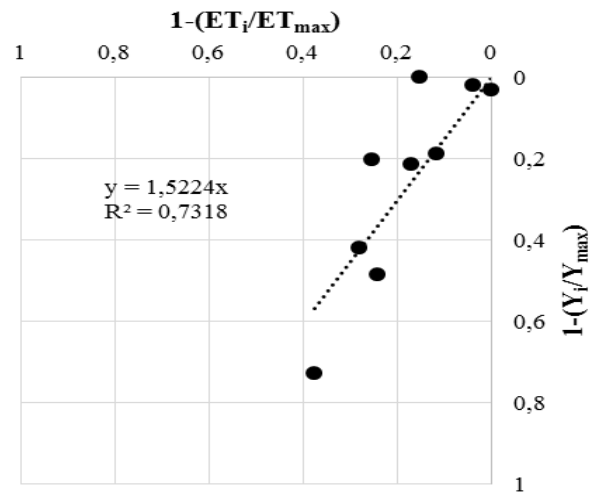

Figure 5. The "yield-evapotranspiration" dependence in FAO methodology

If a linear approximation is considered (Fig. 6ab), then: $Y=a_{1}+b_{1} E T$, $M W U E=$ const. $=2.451 . W U E$ is calculated as $W U E=Y / E T=a_{1} / E T+b_{1}$ and performs a parabola with an asymptote $M W U E=\mathrm{b}_{1}$ (when a $\neq 0$ ) (Fig. 6b), and $E W P$ is calculated as $E W P=b_{1} E T /\left(a+b_{1} E T\right)$ (Fig 6c).

For $E W P>0, W U E$ increases. In this linear relationship $Y_{\max }=a_{1}+b_{1} / E T_{\max }$, i.e. the crop accumulates maximum yield at maximum evapotranspiration.

Then $1-Y / Y_{\text {max }}=b_{1} E T /\left(a_{1}+b_{1} E T\right)\left(1-E T / E T_{\text {max }}\right)$

and $K_{y}=b_{1} E T /\left(a_{1}+b_{1} E T\right)=1.52$.

The crop yield response factor can be calculated directly from the linear expression for $E W P$ by substituting $E T$ with $E T_{\max }$.

In case of a quadric approximation (Fig. 7), then:

$$
\begin{aligned}
& Y=a_{2}+b_{2} E T+c_{2} E T^{2}, \\
& W U E=a_{2} / E T+b_{2}+c_{2} E T, \\
& M W U E=b_{2}+2 c_{2} E T, \\
& E W P=b_{2}+2 c_{2} E T /\left(a_{2}+b_{2} E T+c_{2} E T^{2}\right) .
\end{aligned}
$$


It is seen on Fig. 7b, that with the increase of $E T, M W U E$ decreases linearly; the dependence $W U E-E T$ is a parabola that reaches maximum at $E T=\sqrt{a_{2} / c_{2}}$, then decreases; $Y$ reaches maximum at $E T=-b_{2} / 2 c_{2} ; M W U E$ occurs before the maximum yield. Assuming that the yield $Y$ is maximal at maximum evapotranspiration, then:

$$
\begin{aligned}
& 1-Y / Y_{\text {max }}=-c_{2} E T_{\text {max }}^{2} / Y_{\text {max }}\left(1-E T / E T_{\text {max }}\right)^{2} \text { and } \\
& K_{y}=-c_{2} E T_{\text {max }}^{2} / Y_{\text {max }} .
\end{aligned}
$$

The yield response factor in the quadratic equation is $K_{\mathrm{y}}=4.69$.

The results obtained show that if the objective of the procedure is to obtain a maximum yield $\left(Y_{\max }=4.444 \mathrm{Mg} / \mathrm{ha}\right)$, the evapotranspiration should be maximum $\left(E T_{\max }=310.0 \mathrm{~mm}\right) . E T_{\max }$ is with $12 \%$ higher than $E T$ at $M W U E(268.5 \mathrm{~mm})$, while $Y_{\max }$ is with $6 \%$ higher than $Y$ at $M W U E$.

There are two typical EWP values, proceeding from the quadric approximation. One of them is $E W P=1$ that indicates $M W U E$. The other one is $E W P=0$ that indicates $Y_{\max }$ and $E T_{\max }$.

Calculation of $E W P$ can be useful for indication of the critical range of the seasonal evapotranspiration around which the productivity and the yield would be maximal $(0 \leq E W P \leq 1)$. Further, this information can be used for predicting the needed water amounts for irrigation according to the seasonal weather and precipitation forecasts.

Some local researchers like Davidov $(1982,2004)$ have the opinion that the yield-evapotranspiration relationship has more complicated nature. The calibrated parameters of two Davidov equations for canola are as follows: $a=3.53$ and $k=1.58$ in the single-power equation

$$
\begin{aligned}
& Y_{d e f}^{i} / Y_{\max }=1-3.53\left(1-E T_{\text {def }}^{i} / E T_{\text {max }}\right)^{1.58} \text { (Fig. 8) and } \\
& q=2.39 \text { and } r=13.63
\end{aligned}
$$

in the two-power equation

$$
Y_{d e f}^{i} / Y_{\max }=\left(1-\left(1-E T_{d e f}^{i} / E T_{\max }\right)^{2.39}\right)^{13.63} \text { (Fig. 9). }
$$

Both approximations have very high coefficients of determination, which in turn are much higher than that of FAO linear approximation. The results indicate that the Davidov functions approximate the experimental data more accurately, compared with the quadric function either.

All the calibrated equations can be used for yield prediction for canola but with priority given to Davidov equations. 

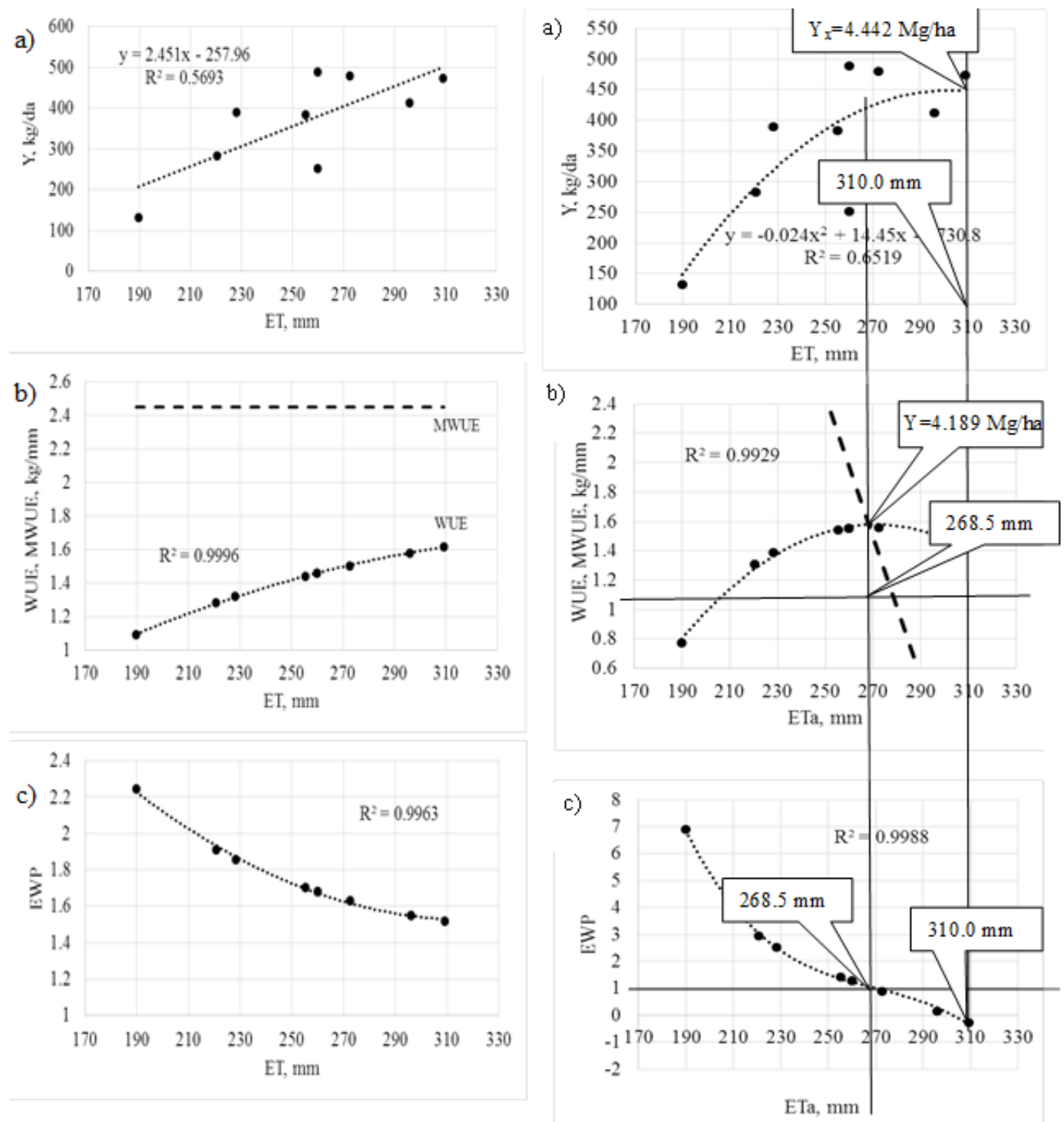

Figure 6. Evapotranspiration-Yield-Water-use efficiency- Maximum water-use efficiencyElasticity relations in a linear approximation of the dependence yield-evapotranspiration

Figure 7. Evapotranspiration-Yield-Water-use efficiency- Maximum water-use efficiencyElasticity relations in a quadratic approximation of the dependence yieldevapotranspiration 


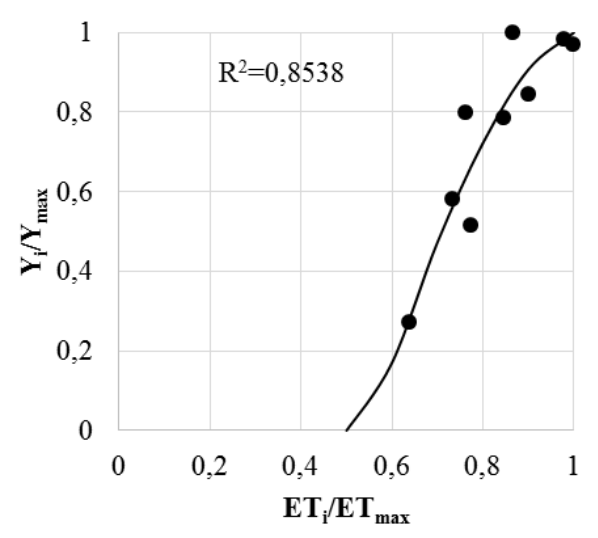

Figure 8. Davidov single-power approximation

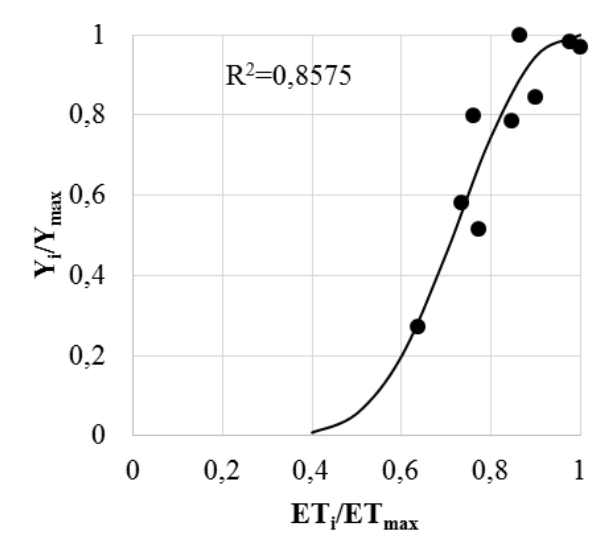

Figure 9. Davidov two-power approximation

\section{CONCLUSIONS}

1. Irrigation has statistically significant impact on canola yield. In a threeyear period, it contributes for seed yield increase from a minimum of $1.319 \mathrm{Mg} / \mathrm{ha}$ under rain-fed conditions to a maximum of $4.889 \mathrm{Mg} / \mathrm{ha}$ under full irrigation.

2. Water use efficiency occurs not with the maximum yield but a bit earlier. The maximum irrigation water use efficiency in the experiment was obtained at an irrigation depth of $94 \mathrm{~mm}$ and was $1.78 \mathrm{~kg} / \mathrm{m}^{3}$. By managing $12 \%$ less (than needed) seasonal evapotranspiration, the yield losses can be only $6 \%$.

3. Elasticity is an indicator for the critical range of the seasonal evapotranspiration, in which the water use efficiency and the yield are maximal $(0 \leq E W P \leq 1)$. This information is useful for prediction of the irrigation water amounts according to the seasonal weather and precipitation forecasts.

4. The yield response factor in FAO linear function is $K_{\mathrm{y}}=1.52$. It indicates canola high sensitivity to water. The parameters of Davidov single-power equation are $a=3.53$ and $k=1.58$. The parameters of Davidov two-power equation are $q=2.39$ and $r=13.63$. Davidov approximations are more accurate than those of FAO linear equation and the quadric function. They are recommended with priority for forecasting canola yields on the base of the seasonal evapotranspiration.

\section{REFERENCES}

Aiken, R. M., F. R. Lamm (2006): Irrigation of oilseed crops. In: Proc. Central Plains Irrigation Conference, Colby, K.S., Feb. 21-22, 2006. Available from CPIA, 760 N. Thompson, Colby, KS. pp. 162-172.

Alberta Agriculture (1980): Irrigated oilseed rape production. Agdex No. 149/561-1. Edmonton, Alberta: Alberta Agriculture.

Davidov, D. (1982): About the "yield-water" dependency. Journal Hydrotechnics and Amelioration, 7: 18-20 (in Bulgarian) 
Davidov, D. (2004): The "yield-water" dependency - comparison and analyses of formulas. Agricultural Engineering, 1: 28-33 (in Bulgarian with an abstract in English)

Doorenbos, J. and Kassam, A.H. (1979): Réponse des rendements à l'eau. Bulletin FAO d'irrigation et de drainage No. 33, Rome, 144 pp.

Downey, L.A. (1972): Water-yield relation for nonforage crops. Jour. of Irrig. And Drain. Div., Proceedings of the ASAE, vol. 98, No. IR 1: 107-115

Fanaei, H.R., M. Galavi, M. Kafi, A. Ghaari Bonjar. (2009) Amelioration of water stress by potassium fertilizer in two oilseed species. International Journal of Plant Production 3 (2), 41-54

Geography of Bulgaria (2002): ForCom, S., 760 pp..

Hexem, R.W., Heady, E.O. (1978): Water Production Functions for Irrigated Agriculture. Iowa State University Press, Ames, IA, $215 \mathrm{pp}$.

Istanbulluoglu, A., B. Arslan, E. Gocmen, E. Gezer, C. Pasa. (2010): Effects of deficit irrigation regimes on the yield and growth of oilseed rape (Brassica napus, L.). Biosystem Engineering, 105, 388-394

Jensen, M.E., (1968): Water Consumption by Agricultural Plants in Water Deficits and Plant Growth. ED T.T. Kozlovski, vol. II, Acad. Press, NX 1-22.

Kostyakov, A.N. (1951): Theoretical basis of irrigation and drainage, Selhodgiz, M., 751 pp. (in Russian)

Liu, W.Z. D.J. Hunsaker, Y.S. Li, X.Q. Xie, G.W. Wall. (2002): Interrelations of yield, evapotranspiration, and water use efficiency from marginal analysis of water production functions. Agricultural Water Management 56 (2002) 143-151

North, S. (2010): Tactical Irrigation Strategies for Maximizing Farm Profitability in Mixed Cropping Enterprises. Irrigation Matter Series No. 03/10, Cooperative Center for Irrigation Futures.

Poare, M, Ch. Olivier (1969): Irrigation. Irrigation Systems. Theory, Equpment and Economics of Irrigation. S. Zemizdat, 371 pp. (in Bulgarian)

Rafailov, R., Y. Banov, B. Kolev (1998): The impact of moisture regime in haplic chernozems on the yield of maize grain. Soil Science, Agro-Chemistry and Ecology, 33, 5: 1417.

Stewart, J. I., Hagan, R.M. (1973): Functions to predict effects of crop water deficits. Journal of the Irrigation and Drainage Division, ASCE, vol. 99, No. IR 4: 421-439

Tsakiris, G.P. (1981) ICID. 11th Congress, Grenoble, C.2, p. 9-28

Varlev, I., Z. Popova (1999): Water - Evapotranspiration - Yields, C. 144 c.

Varlev, I. (2004): Use of the dependences "yield-water" in the irrigation practice. Soil Science, Agro-Chemistry and Ecology, 34, 1: 36-43

Zhivkov, Zh. (1994): About the productivity of maize grain in water shortage conditions. Plant Science, 21, 1-2: 15-18

Zhivkov, Zh. (1995): Maize grain growing under maximum and deficit water supply for irrigation. Plant Science, 32, 9-10: 142-145

Zhivkov, Zh., D. Davidov (2003): Interrelations between the yield, evapotranspiration and the irrigation depth at maize grain. Proc. Int. Conf. "50th Anniversary of the Forestry University, 1-2 April 2003, Agronomy Section: 142-148

Vaux Jr., H.J., Pruitt, W.O. (1983): Crop-water production functions. In: Hillel, D. (Ed.), Advances in Irrigation, Vol. 2. Academic Press, New York, pp. 61-97. 